“ (C) 2017 IEEE. Personal use of this material is permitted. Permission from IEEE must be obtained for all other uses, in any current or future media, including

reprinting/republishing this material for advertising or promotional purposes, creating new collective works, for resale or redistribution to servers or lists, or reuse of any copyrighted component of this work in other works." 


\title{
Parameter Analysis of a New AFIPM for Light Electric Vehicle Application
}

\author{
Chengcheng Liu',2, Youhua Wang ${ }^{1,2}$, Gang $\mathrm{Lei}^{3}$, Bo $\mathrm{Ma}^{3}$, Youguang $\mathrm{Guo}^{3}$, and Jianguo $\mathrm{Zhu}^{3}$ \\ ' Province-Ministry Joint Key Laboratory of EFEAR, Hebei University of Technology, Tianjin 300130 \\ ${ }^{2}$ State Key Laboratory of Reliability and Intelligence of Electrical Equipment, Hebei University of Technology, \\ Tianjin 300130 \\ ${ }^{3}$ School of Electrical, Mechanical and Mechatronic System, University of Technology, Sydney, NSW 2007, Australia
}

\begin{abstract}
The electrical machines are gaining more and more attentions nowadays, especially for the electric vehicle application. Compared with the radial flux machine, the axial flux machine can have higher torque density and efficiency due to its tight structure. However, most of the axial flux machines are designed with the surface mounted permanent magnets (PMs) rotor, where the reluctance torque ability is reduced. To improve the torque ability of the axial flux machine, a new axial flux interior permanent magnet machine (AFIPM) is proposed and analyzed in this paper. The rotor of the proposed AFIPM is manufactured by the rolling the electrical steels as a ring core, then the PMs are inserted in the holes of the rotor ring, the axial side of the rotor ring is designed with the several different steps to eliminate the harmonics of the back EMF as well. The static performance and electromagnetic parameters of the AFIPM is calculated and it shows that the reluctance torque ability of the AFIPM is very good, based on the 3D finite element method (FEM) and frozen magnetic permeability technology.
\end{abstract}

Index Terms--Electrical machine, electric vehicle, axial flux machine (AFM), 3-D finite element method (FEM).

\section{INTRODUCTION}

Nowadays environment pollution and energy shortage become more and more critical in the world. To solve this problem, the new energy generation technology and electrical vehicle are the two most important ways [1-2]. The electrical machine plays a very important role in the electric vehicle, now it gains more and more attentions. The key requirement of electrical machine for the electric vehicle application can be summarized as follows: 1) high power density, 2) high efficiency, 3) good robust, and 4) wide constant power speed range ability [3-4].

In the past decades, various kinds of topologies of the electric vehicles are proposed and studied, where including the pure electric vehicle, hybrid electric vehicle, and fuel cell electric vehicle [5-8]. For the pure electric vehicle, both the direct drive electric vehicle and non direct drive electric vehicles were investigated and prototyped. The most advantage of the direct vehicle is the saving of the gear box and thus the weight and the cost of vehicles can be reduced. For this kind of vehicle, the various kinds of electrical machines were designed and analyzed, including the outer rotor surface mounted permanent magnet machine, axial flux machine, etc [910]. To improve the performance of the direct drive machines, their number of pole pairs is always designed with a high number.

As a mechanical system, the electric vehicle should be redesigned for the direct drive mode, because of the weight of wheel of the vehicle is increased. Until now, most of the vehicle company still use the old vehicle structure to design the new electric vehicle. Therefore, electrical machines for the traditional electric vehicle is still of a hot topic, including the induction machine, interior permanent magnet radial flux machine, switch reluctance machine, direct current machine etc. Some new machines are proposed as well, including the flux switching permanent machine, axial flux machine, and transverse flux machine. Among them the axial flux machine can have higher torque ability and efficiency due to its tight structure.

During the last years, the research for the axial flux machine is very hot. However, most of them were discussed on the stator core and winding design, and seldom of them on the rotor design. The main reason is that people want to keep the structure of the axial flux machine and as short axial length as possible, and thus the only surface mounted permanent magnet rotor were studied. The problem is the manufacturing for this rotor back iron is quite difficulty, and sometimes they will be replaced by a iron plate which can introduce very high eddy current loss, and the surface mounted rotor make the axial flux machine without of the reluctance torque ability which confines the improving of the torque ability of the axial flux machine [11-12].

To improve the torque ability of the axial flux machine, a new axial flux interior permanent magnet machine is designed and proposed in this paper. The topology of the AFIPM is introduced in the section II, then followed by the $3 \mathrm{D}$ magnetic field density analysis based on the finite element method, structure improvement and optimization, parameter analysis based on the frozen permeability technology and performance calculation.

\section{TOPOLOGY OF THE NEW DEVELOPED AFIPM}

The AFIPM is with the single stator core and single rotor core structure as shown in Fig. 1. The winding of the AFIPM is the distributed winding similar to the traditional interior permanent magnet radial flux machine, the advantage is that the leakage inductance is quite low and it can make the machine with high power factor. The stator slot of the AFIPM is the half closed slot, thus the 
winding can be inserted conveniently and there more permanent magnet flux can be penetrated into the stator teeth then the magnetic load can be improved. Both the stator core and the rotor core are manufactured by rolling the electric steels as a cylinder hoop. For the mass production the electric steels will be punched with a proper structure, while for the laboratory production the line cutting method will be applied to manufacture the cylinder hoop to the determined structure as the stator or rotor. The complete rotor can be obtained by inserting the permanent magnets into the hole of the rotor core, as shown in Fig. 1(b). In this paper, the stator slots and pole number is chosen as 36 and 8 respectively. As shown, the rotor teeth are designed with several different height steps to eliminate the harmonics. The more detailed rotor teeth can be shown in Fig. 2(b), it can be found that the design consideration of the AFIPM is quite similar to the radial flux IPM, where the magnetic barrier is designed to reduce the leakage magnetic flux form the PM. In the prototype, the magnetic part of the rotor of AFIPM will be enclosed by the stainless steels, thus the strength of the rotor will be improved.

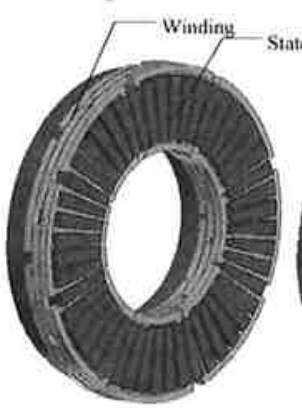

(a)

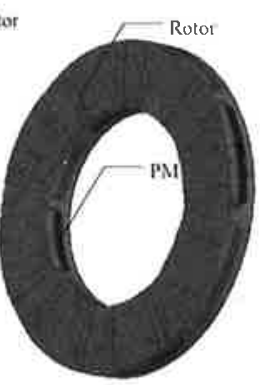

(b)

Fig. 1. Main topology of the new axial flux interior permanent magnet machine, (a) stator and winding, (b) rotor and PM

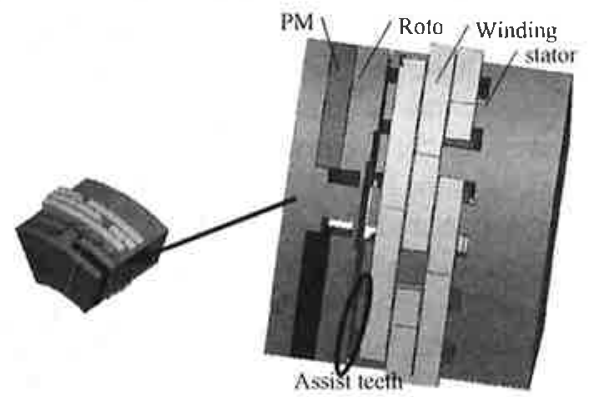

(a)

(b)
Fig. 2. Calculation model of the new AFIPM, (a) region and (b) detailed model

\section{3D MAGNETIC FIELD ANALYSIS}

To accurately analyze the magnetic parameter and performance of the AFIPM, the 3D magnetic field analysis is applied, based on 3D finite element method (FEM). For reducing the computation load and improve the calculation efficiency, the $1 / 8$ model is used as shown in Fig. 2(a), and the master and slavery boundary is used.

Fig. 3 shows the no load magnetic flux density distribution of the AFIPM, it can be seen that the magnetic flux density in the stator teeth can reach to $1.4 \mathrm{~T}$ and the back iron and magnetic barrier of the rotor core saturates to $2.0 \mathrm{~T}$.
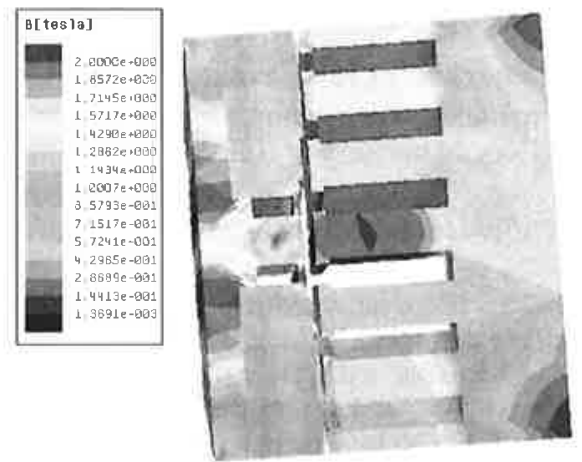

Fig. 3. No load magnetic flux density distribution of the AFIPM

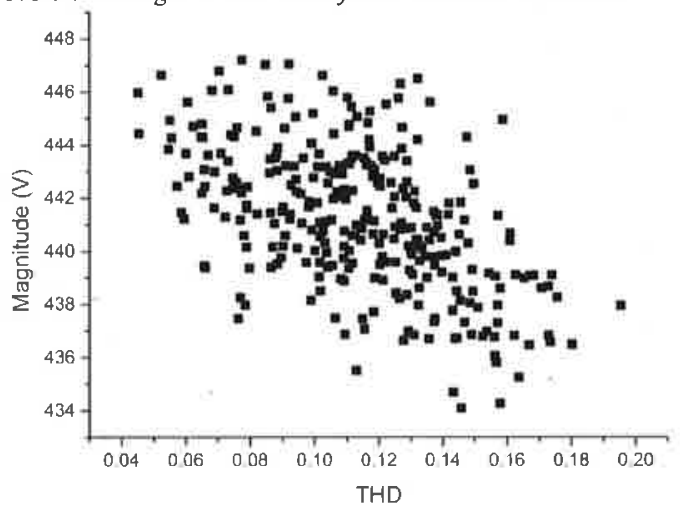

Fig. 4. Scatters of the back emf of the AFIPM with different parameters

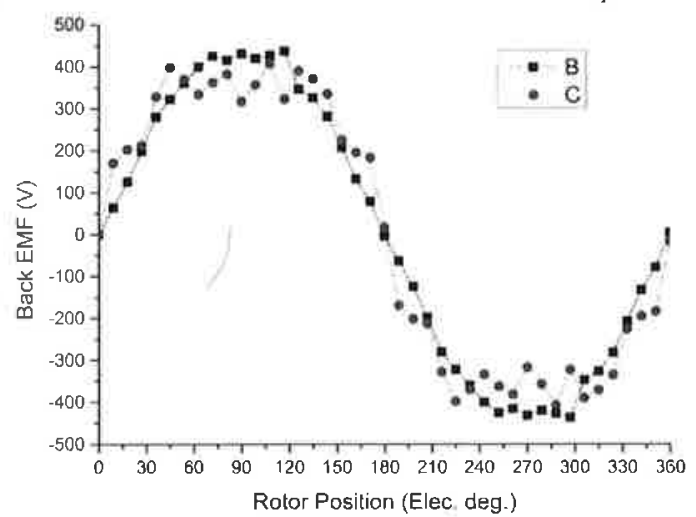

Fig. 5. Comparison of the back EMF waveform of the optimized AFIPM and the initial one

\section{DESIGN OPTIMIZATION OF AFIPM}

To improve the performances of the proposed AFIPM, optimization is necessary. In the AFIPM, there are many dimensions needs to be determined and many optimization method can be applied [13-18]. This section will investigate the optimization problem of this AFIPM. The most important of them may be concluded as the width of the PM and the rotor teeth. To maximize the performance of AFIPM, the width of the PM is chosen as the 36 degs in both rotor inner radius and outer radius side. As a very important parameter, the back Emf waveforms determine the performance of the permanent 
magnet machine, it is because the higher the magnitude of the back Emf the higher the output and the less the back Emf harmonics the lower the iron loss in the stator core and thus the higher efficiency of the machine. Based on this assumption, the dimension of the rotor teeth of the AFIPM is optimized, as shown in Fig. 4, the back Emf performance of the AFIPM with different rotor teeth are quite different. Based on this figure, the optimal design of the rotor teeth can be chosen. Fig. 5 and Fig. 6 show the back Emf characteristic of the AFIPM with the initial design and optimized design respectively, it can be seen that the magnitude of the back Emf is improved and harmonics is reduced greatly especially the $3^{\text {rd }}$ harmonics in the optimized AFIPM. Table I lists the main dimension of the AFIPM. It can be found in Table I that the designed rated current density of AFIPM is $8 \mathrm{~A} / \mathrm{mm}^{2}$ and the slot fill factor of 0.65 . in the design of AFIPM in this paper, no further special coolant method is utilized to lower the temperature rise.

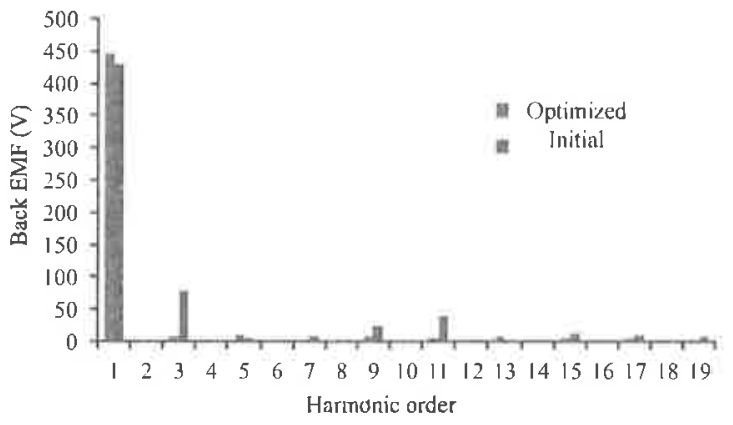

Fig. 6. Comparison of the back EMF harmonics of the optimized AFIPM and the initial onc

Table [

Dimension and Parameters of AFIPM

\begin{tabular}{|c|c|c|}
\hline Parameter & Value & Unit \\
\hline Stator (rotor) outer radius & 134.62 & $\mathrm{Mm}$ \\
\hline Stator (rotor) inner radius & 80 & $\mathrm{Mm}$ \\
\hline Rotor axial length & 25 & $\mathrm{Mm}$ \\
\hline Stator axial length & 59 & $\mathrm{Mm}$ \\
\hline Stator slot length & 26 & $\mathrm{Mm}$ \\
\hline Stator teeth length & 3 & $\mathrm{Mm}$ \\
\hline Stator slot width & 7 & $\mathrm{Mm}$ \\
\hline Number of rotor poles & 8 & \\
\hline Number of winding turns & 20 & \\
\hline Length of rotor step outer teeth & 1 & $\mathrm{Mm}$ \\
\hline Length of rotor step inner teeth & 1 & $\mathrm{Mm}$ \\
\hline Rotor step outer teeth angle & 33 & $\mathrm{Deg}$ \\
\hline Rotor step inner teeth angle & 24 & $\mathrm{Deg}$ \\
\hline PM outer angle & 36 & $\mathrm{Deg}$ \\
\hline PM inner angle & 36 & $\mathrm{Deg}$ \\
\hline Air gap length & 0.78 & $\mathrm{Mm}$ \\
\hline Thickness of rotor magnetic & 1.8 & $\mathrm{Mm}$ \\
\hline barricr & & \\
\hline PM thickness & 8 & $\mathrm{Mm}$ \\
\hline Raled current density & 8 & $\mathrm{~A} / \mathrm{mm}{ }^{2}$ \\
\hline Slot fill factor & 0.65 & \\
\hline Rated speed & 3000 & $\mathrm{Rpm}$ \\
\hline
\end{tabular}

\section{Parameter CAlCulation AND PERFormance CALCULATION}

\section{A. No Load Calculation}

In the design of PM machine, the PM flux linkage per turn, the inductance characteristics and cogging torque are very important, especially in the interior permanent magnet machine, because of the torque ability of the IPM is determined by both the permanent magnet torque and the reluctance torque, it can be calculated by

$$
T_{c}=T_{\mathrm{l} M \mathrm{M}}+T_{\mathrm{rcl}}=\frac{3}{2} p\left[\psi_{1} \mathrm{MI}_{i q}+\left(L_{d}-L_{q}\right) i_{d} i_{q}\right](1)
$$

For the ideal IPM the maximum electromagnetic torque can be achieve when the id equals iq, when the permanent magnet torque and the reluctance torque contribute the same effect.

Fig. 7 shows the PM flux per turn of the AFIPM, Fig. 8 shows the self inductance and the mutual inductance of the AFIPM, and Fig. 9 shows the cogging torque waveforms of the AFIPM.

It can be calculated that the $\mathrm{d}$ and $\mathrm{q}$ axis inductance per turn is 0.01875 and $0.04125 \mathrm{mH}$ respectively. Thus, based on the no load parameter analysis, we can find that the permanent magnet torque and reluctance torque at the rated load is $120 \mathrm{Nm}$ and $94.8 \mathrm{Nm}$. It can give us a very good result. However, when the armature current is applied in the IPM, the magnetic saturation will occurs and then the effective permanent magnetic flux will be reduced and the self inductance of the IPM will be reduced as well. To analyze the performance of the AFIPM more thoroughly, the parameter of the AFIPM under the different load are analyzed as well.

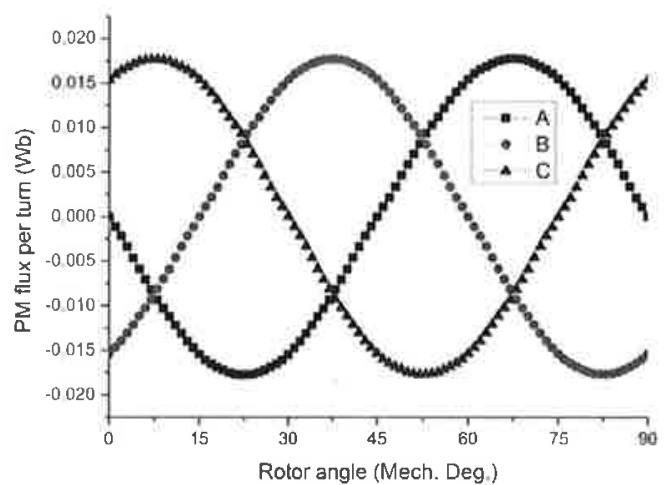

Fig. 7. PM flux per turn of the AFIPM

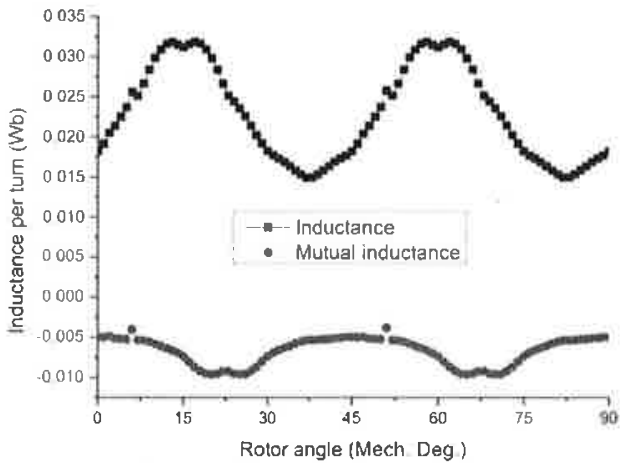

Fig. 8. Inductance of the AFIPM 


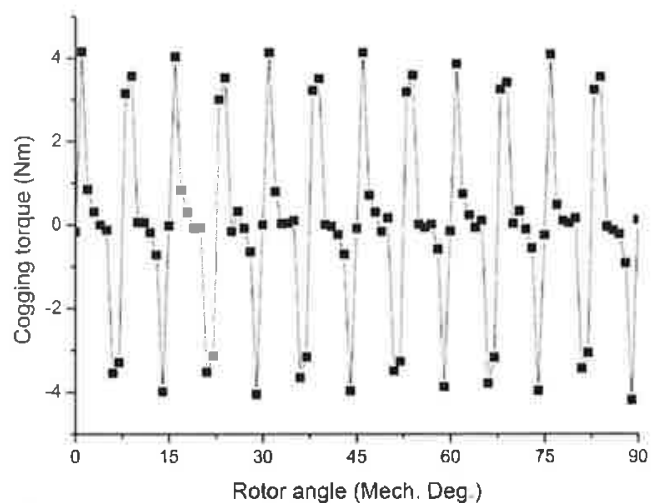

Fig, 9. Cogging torque of the AFIPM

\section{B. Different Load Calculation}

In this paper, the frozen permeability technology is used to calculate the inductance, thus the inductance of the AFIPM with the different current load is quite different from each other. In this section, the magnetic parameter of AFIPM under the different load is analyzed.

Firstly, the parameters when the $q$ axis current is zero but the $\mathrm{d}$ axis current changes are investigated. By using the above mentioned method, the self inductance, mutual inductance and electromagnetic torque of the AFIPM under only $q$ axis current changes are shown in Fig. 10, 11 and 12 respectively. It can be seen that the self inductance of the AFIPM do not varied much when the $d$ axis current increase, while the mutual inductance changed greatly. As for the electromagnetic torque, the value increases with the $\mathrm{d}$ axis current increase but the phase and the shape do not. The cogging torque is resulted by the interaction of the permanent magnet (PM) and the stator slot, form the definition it is only existed in the PM machine. However, some people referred that the switch reluctance machine can also have the cogging torque. In this paper, the electromagnetic torque produced by the $d$ axis current and $q$ axis current equals zero can be regarded as the cogging torque, because of its average value is zero.

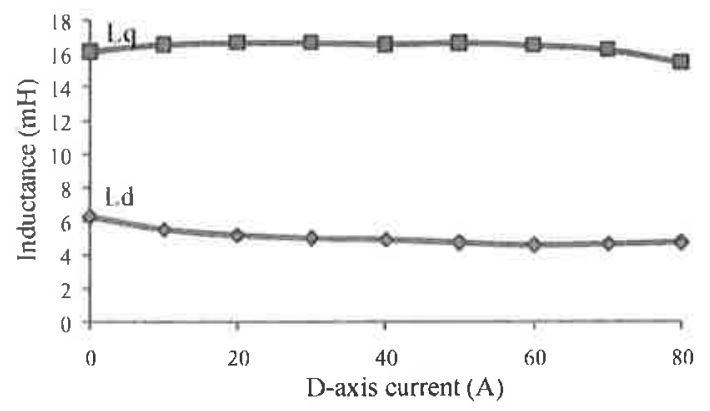

Fig. 10. D-axis and Q-axis inductance of the AFIPM with the $q$ axis current equals zero but d axis current increases from $0 \mathrm{~A}$ to $80 \mathrm{~A}$

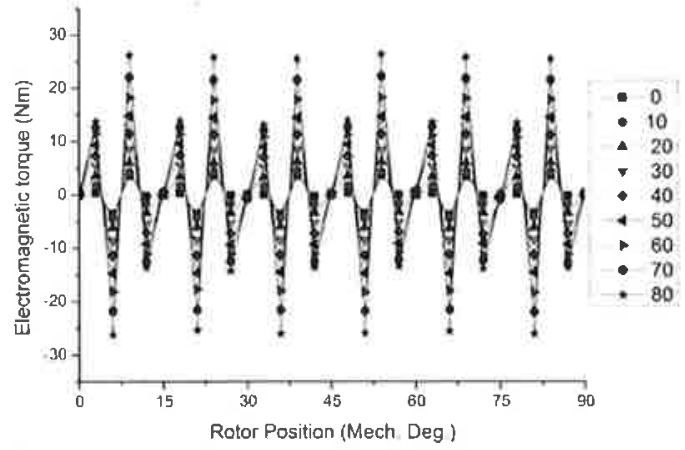

Fig. 11. Electromagnetic torque of the AFIPM with the $q$ axis cultent equals zero but $\mathrm{d}$ axis current changes from $0 \mathrm{~A}$ to $80 \mathrm{~A}$

The self inductance, mutual inductance and electromagnetic torque in the AFIPM when the $d$ axis current equals zero and only the $\mathrm{q}$ axis current varies can be shown in Fig. 13, 14 and 15. Different from the above analysis, the inductance waveform changes greatly, it can be seen that both the self inductance and mutual inductance decreases with the $q$ axis current increases. Fig. 15 shows the PM torque with the current increase, it can be seen that only the no load parameter analysis is not enough for the accurate performance calculation of the AFIPM. As shown in Fig. 15, the torque ripple increases with the $q$ axis current increase, it resulted by the harmonics of the PM flux, the harmonics of the PM flux will be increase with the q-axis current increase.

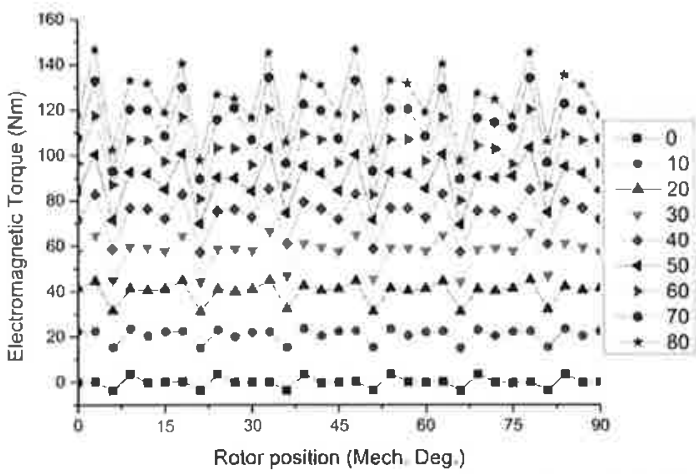

Fig 12. Electromagnetic torque of the AFIPM with the $d$ axis current equals zero but $q$ axis current changes from $0 \mathrm{~A}$ to $80 \mathrm{~A}$

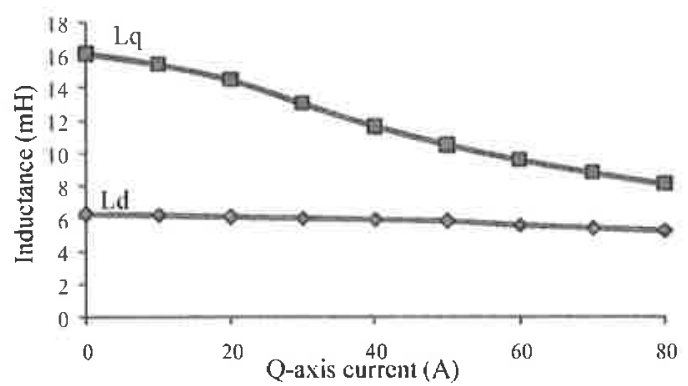

Fig. 13. D-axis and Q-axis inductance of the AFIPM with the $d$ axis current equals zero but $\mathrm{q}$ axis current changes from $0 \mathrm{~A}$ to $80 \mathrm{~A}$

\section{Electromagnetic Torque Characteristic}

By using the electromagnetic parameter obtained in the 
above sections and the electromagnetic torque calculation method of the PM machine, the electromagnetic torque of AFIPM with the different phase current and phase angle can be calculated, as shown in Fig. 16. It can be found that the maximum torque of the AFIPM will be achieved when the phase angle of the current equals 30 degs at the current of $60 \mathrm{~A}$. The torque characteristic of the AFIPM is quite close to the ideal IPM for the commercial usage, e.g. the IPM for Prius vehicle. It can be also seen that the PM torque will not increase linearly with the phase current increase, because of the PM flux will saturates when the phase current increase.

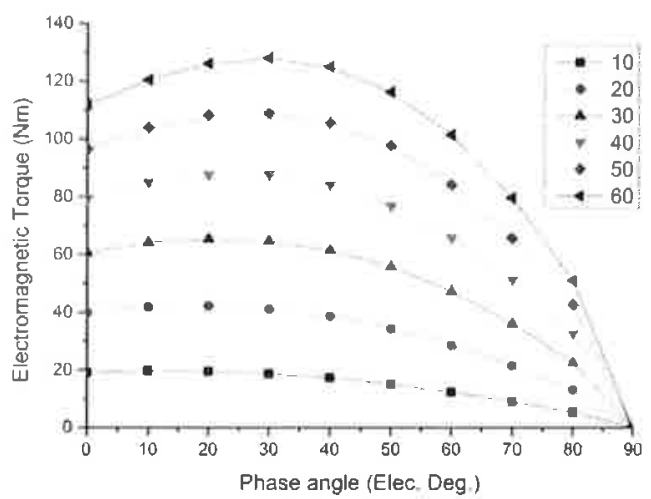

Fig. 14. Electromagnetic torque of AFIPM with the phase current and phase angle changes

\section{Conclusions}

A new axial flux interior permanent magnet machine is designed and developed in this paper, it working principles are explained and the advantages of this machine is shown by using the finite element analysis method. However, the saturation of the rotor for the single side AFIPM is a serious problem, in the future work we will develop a single rotor double side stator AFIPM. Further, considering the stator of the AFIPM can be moved to close or far to the rotor, the mechanical flux weakening AFIPM will be investigated in the future as well.

\section{ACKNOWLEDGMENT}

This work was supported by National Natural Science Foundation of China (NSFC), under Grant 51377042.

\section{REFERENCES}

[1] C. H. T. Lee; K. T. Chau; C.H. Liu, "Design and analysis of an electronic-geared magnetless machine for electric vehicles" IEEE Transactions on Industrial Electronics, vol. 63 no. 11, pp. 6705-6714, Nov 2016

[2] Y.T. Gao; R.H. Qu; D.W. Li; J. Li; G.P. Zhou, "Consequent-pole flux-reversal permanent-magnet machine for electric vehicle propulsion" IEEE Transactions on Applied Superconductivity, vol. 26 no. 4, article number. 16356435, June 2016

[3] C. C. Chan, "The state of the art of electric, hybrid, and fuel cell vehicles," Proc. IEEE, vol. 95, no. 4, pp. 704-718, Apr. 2007.
[4] Z. Q. Zhu and D. Howe, "Electrical machines and drives for electric, hybrid, and fuel cell vehicles," Proc. IEEE, vol. 95, no. 4, pp. 746-765, Apr. 2007.

[5] C.C. Liu, J.G. Zhu, Y.H. Wang and et al. "Comparison of electrical machines with SMC core", IEEE transactions on industrial electronics, Volume: 64, Issue: 2, Feb. 2017

[6] Xiaodong Sun, Long Chen, Zebin Yang. "Overview of bearingless permanent magnet synchronous motors". IEEE Transactions on Industrial Electronics, 2013, 60(12): 55285538 .

[7] H. Kim;Y.J. Li;B. Sarlioglu, "Novel six-slot four-pole axial flux-switching permanent magnet machine for electric wehicle" IEEE Transactions on Transportation Electrification, vol. 3 no. 1, pp. 108-117, March 2017

[8] G. Pellegrino, A. Vagati, P. Guglielmi, and B. Boazzo, "Performance comparison between surface mounted and interior PM motor drives for electric vehicle application," IEEE Trans. Ind. Electron., vol. 59, no. 2, pp. 803-811, Feb. 2012.

[9] B. Sarlioglu and C. T. Morris, "More electric aircraft: Review, challenges, and opportunities for commercial transport aircraft," IEEE Trans. Transport. Electrific., vol. 1, no. 1, pp. 54-64, Jun. 2015

[10] L. Hao, M. Lin, X. Zhao, X. Fu, Z. Q. Zhu, and P. Jin "Static characteristics analysis and experimental study of a novel axial field flux switching permanent magnet generator," IEEE Trans. Magn., vol. 48, no. 11, pp. 42124215, Nov. 2012.

[11] J. H. Kim, Y. Li, E. Cetin, and B. Sarlioglu, "Cogging torque minimization with rotor tooth shaping in axial fluxswitching permanent magnet machine," in Proc. IEEE Energy Convers. Congr. Expo., Sep. 2016.

[12] R. Cao, C. Mi, and M. Cheng, "Quantitative comparison of flux switching permanent-magnet motors with interior permanent magnet motor for $\mathrm{EV}, \mathrm{HEV}$, and $\mathrm{PHEV}$ applications," IEEE Trans. Magn., vol. 48, no. 8, pp. 2374 2384, Aug. 2012.

[13] G. Lei, J. G. Zhu, Y. G. Guo, K. R. Shao and W. Xu "Multi-objective sequential design optimization of PMSMC motors for Six Sigma quality manufacturing," IEEE Transactions on Magnetics, vol. 50, no. 2. Feb. 2014, Art. no. 7017704 .

[14] G. Lei, J. G. Zhu, Y. G. Guo, Wei Xu and K. R. Shao, "Multi-objective sequential optimization method for the design of industrial electromagnetic devices," IEEE Transactions on Magnetics, vol. 48, no. 11, pp. 4538-4541, 2012.

[15] G. Lei, W. Xu, J. F. Hu, J. G. Zhu, Y. G. Guo and K. R. Shao, "Multilevel design optimization of a FSPMM drive system by using sequential subspace optimization method," IEEE Transactions on Magnetics, vol. 50, no, 2, Feb. 2014, Art. no. 7016904.

[16] G. Lei, Y. G. Guo, J. G. Zhu, X. M. Chen, and W. Xu, "Sequential subspace optimization method for electromagnetic devices design with orthogonal design technique," IEEE Transactions on Magnetics, vol. 48, no. 2, pp. 479-482, 2012.

[17] G. Lei, G. Y. Yang, K. R. Shao, Y. G. Guo, J. G. Zhu, and J. D. Lavers, "Electromagnetic device design based on RBF models and two new sequential optimization strategies," IEEE Transactions on Magnetics, Vol. 46, No. 8, pp. 3181 3184,2010

[18] G. Lei, K. R. Shao, Y. G. Guo, J. G. Zhu, J. D. Lavers, "Improved sequential optimization method for high dimensional electromagnetic optimization problems," IEEE Transactions on Magnetics, Vol. 45, No. 10, pp. 39933996, 2009. 
